\title{
Magnitude and Obstetric Complications of Twin Deliveries at Nekemte Referral Hospital, Western Ethiopia: Facility-Based Case Control Study
}

\author{
Amaru Ayza ${ }^{*}$, Temesgen Tilahun ${ }^{2}$ and Dechasa Bedada ${ }^{3}$ \\ ${ }^{1}$ Emergency Obstetrics, Gynecology and General Surgery, Bitana Primary Hospital, Ethiopia; ${ }^{2}$ Institute of Health Sciences, Wollega \\ University, Nekemte, Ethiopia; ${ }^{3}$ College of Public Health and Medical Sciences, Jimma University, Jimma, Ethiopia
}

\begin{abstract}
Background: Twin pregnancy is a high-risk pregnancy with increased risk of obstetric complications.

Objective: This study is to identify magnitude and obstetric complications of twin deliveries at Nekemte Referral Hospital.

Method: Hospital-based unmatched case-control study design was carried-out on 104 sets of twin deliveries as cases and 208 singleton deliveries as controls conducted in obstetrics ward of Nekemte Referral Hospital from March 1, 2016 to February 29, 2017. The data were collected through pretested structured questionnaires and analyzed using SPSS version 20.0. The association between twin delivery and different variables were assessed by using Odds Ratio (OR) along with 95\%CI.

Results: The magnitude of twin deliveries was 28.6 in 1000 deliveries. The odds ratio of twin deliveries were significantly higher for the occurrence of hypertensive disorders of pregnancy, gestational diabetes mellitus, preterm delivery, pre-mature rupture of membrane, antepartum hemorrhage, cesarean delivery, anemia, postpartum hemorrhage, sepsis, and cord prolapse when compared to singleton deliveries.

Conclusion: The magnitude of twin delivery in this study was high and numerous maternal complications were identified when compared to singleton deliveries. Thus, twin deliveries need greater attention during pregnancy, delivery and after delivery.
\end{abstract}

Keywords: Obstetric complications; Twin delivery; Singleton delivery

\section{INTRODUCTION}

Twin pregnancy is a type of multiple birth in which the mother gives birth to two babies from the same pregnancy. It usually resulted from fertilization of two separate egg cells and rarely from single fertilized ovum. Its magnitude is generally increasing and varies across human populations [1-3].

Both the anatomic and physiologic changes of twin pregnancy vary from that of singleton pregnancy. Because of this fact, it is associated with increased risk of maternal and fetal complications both in the developed and developing countries. This is probably worse in sub-Saharan Africa, where quality and access to health facility is questionable and poverty is deep rooted [2-8].

In addition to high maternal, fetal and newborn morbidities, twin pregnancy causes more deaths to mother, developing fetus and babies when compared to singleton delivery [4]. Despite its clinical and public importance, studies on the outcomes of twin deliveries and associated maternal complications are confined to few teaching hospitals in Ethiopia. Thus, it is very important to have baseline study on this issue in western Ethiopia.

\section{MATERIALS AND METHODS}

\section{Study area, period and setting}

The study was conducted in Nekemte Referral Hospital from March 1, 2016 to February 29, 2017 which is found in Nekemte town 331 $\mathrm{km}$ west of Addis Ababa. The hospital was established in 1923 and is giving services for more than 2 million people. It is also serving as a clinical post graduate attachment site for medical students, other health science and postgraduate students in Integrated Emergency Obstetrics, Gynecology and General Surgery (IEOS).

Correspondence to: Amaru Ayza, MSC in Integrated Emergency Obstetrics, Gynecology and General Surgery at Bitana Primary Hospital, Ethiopia, Tel: +251912034924; E-mail: amaruayza@gmail.com

Received: November 19, 2018, Accepted: December 03, 2018, Published: December 10, 2018

Citation: Ayza A, Tilahun T, Bedada D (2018) Magnitude and Obstetric Complications of Twin Deliveries at Nekemte Referral Hospital, Western Ethiopia: Facility-based Case Control Study. Biol Med (Aligarh) 11:454. doi:10.35248/0974-8369.19.11.454

Copyright: ( 2018 Ayza A, et al. This is an open-access article distributed under the terms of the Creative Commons Attribution License, which permits unrestricted use, distribution, and reproduction in any medium, provided the original author and source are credited. 
Currently, the hospital has 178 beds and providing medical, surgical, gynecology, obstetrics, pediatrics, radiology, laboratory, pharmacy, psychiatry, and physiotherapy services for patients. Gynecology and obstetrics department is led by team of health professionals (2 Gynecologist, 2 IEOS, and 20 midwives).

\section{Study design}

Hospital based retrospective case control study design was conducted.

\section{Study population}

All women registered in log books and have cads, who gave birth in Nekemte Referral Hospital from March 1, 2016 to February 29, 2017. Cases were all twin deliveries whereas Controls were mothers who gave birth to singleton babies after 28 weeks of gestational age.

\section{Sample size and sampling techniques}

Sample size was calculated by using Epi info version 7.2.0.1 by considering two-population comparisons of proportions based on the following assumptions. Premature Rupture of Membrane (PROM) was taken as one of outcome variables (maternal complications). The proportion of mothers developing PROM among twin deliveries is assumed to be $15.3 \%(\mathrm{p} 1=0.153)$ and singleton deliveries is assumed to be $3.1 \%(\mathrm{p} 2=0.03)$ [5]. A level of confidence of $95 \%$, power of $90 \%$, ratio of cases to controls of $1: 2$ and $10 \%$ non-responses are considered. This gives sample size, 104 cases (twin deliveries) and 208 controls (singleton deliveries), a total of 312 deliveries. For each twin delivery, two singleton deliveries were clerked by using simple random sampling technique.

\section{Data collection procedures}

A pre-tested structured questionnaire was developed after reviewing similar literatures for the data collection. Two midwives and three nurses were recruited and trained on how to collect and fill maternal data obtained from delivery log books and mothers. All completed questionnaires were checked for completeness by the principal investigator.

\section{Ethical consideration}

The ethical clearance was obtained from the Ethics Review Committee of the College of Public Health and Medical Sciences of Jimma University. After explaining the procedure and purposes of the study to the hospital manager and medical director, permission to clerk the study participants and access to obstetric records and logbooks was obtained from Nekemte Referral Hospital. All the information collected from the registry was handled confidentially through omitting their personal identification and the data were used only for the research purpose.

\section{RESULTS}

\section{Socio-demographic and obstetric characteristics at Nekemte Referral Hospital}

A total of 4328 deliveries were conducted at Nekemte Referral Hospital from March 1, 2016- February 29, 2017, out of which 124 were twin deliveries, making 28.6 twin deliveries in 1000 deliveries. Majority of the deliveries (both twin and singleton) were from rural areas, age category of 25 to 29 years and Para II-IV (Table 1).

\section{Maternal complications of twin deliveries at Nekemte Referral Hospital}

The major antepartum complications in twin deliveries when compared to singleton deliveries were hypertensive disorder of pregnancy $(\mathrm{OR}=2.1 ; 95 \% \mathrm{CI}: 1.54,2.86)$, gestational diabetes mellitus ( $\mathrm{OR}=3.03 ; 95 \% \mathrm{CI}: 2.59,3.56)$, premature rupture of membrane $(\mathrm{OR}=1.87 ; 95 \% \mathrm{CI}: 1.28,2.73)$, preterm delivery $(\mathrm{OR}=2.76 ; 95 \% \mathrm{CI}: 2.12,3.40)$, and ante partum hemorrhage $(\mathrm{OR}=1.80 ; 95 \% \mathrm{CI}: 1.09,2.99)$ respectively.

The likelihood of developing intrapartum and postpartum complications like Cesarean delivery $(\mathrm{OR}=2.50 ; 95 \% \mathrm{CI}: 1.88$, 3.34), anemia $(\mathrm{OR}=1.77 ; 95 \% \mathrm{CI}: 1.24,2.52)$, post-partum hemorrhage $(\mathrm{OR}=1.27 ; 95 \% \mathrm{CI}: 0.77,2.11)$, puerperal sepsis $(\mathrm{OR}=2.1895 \% \mathrm{CI}: 1.46,3.25)$ and cord prolapse(OR=2.33; 95\% CI: $1.51,3.84)$ were significantly higher among twin deliveries as compared to singleton deliveries. On the other hand, the risk of developing obstructed labor is lower in twin deliveries (Table 2).

Table 1: The socio-demographic and obstetric characteristics of mothers who delivered at Nekemte Referral Hospital from March 1, 2016 to February 29, 2017.

\begin{tabular}{|c|c|c|c|c|}
\hline \multicolumn{2}{|c|}{ Socio-demographic and obstetric factors } & \multirow{2}{*}{$\begin{array}{c}\text { Cases (Twin) } \mathrm{N}(\%) \\
37(35.6)\end{array}$} & \multirow{2}{*}{$\begin{array}{c}\text { Controls (Singleton) N (\%) } \\
101(48.6) \\
\end{array}$} & \multirow{2}{*}{$\begin{array}{c}\text { Total }(\mathrm{n}=312) \mathrm{N}(\%) \\
138(44.2) \\
\end{array}$} \\
\hline Recidence ore & Urban & & & \\
\hline Kesidence area & Rural & $67(64.4)$ & $107(51.4)$ & $174(55.8)$ \\
\hline \multirow{6}{*}{ Age in years } & $15-19$ & $3(2.9)$ & $14(6.7)$ & $17(5.4)$ \\
\hline & $20-24$ & $30(28.8)$ & $73(35.1)$ & $103(33)$ \\
\hline & $25-29$ & $42(40.4)$ & $88(42.3)$ & $130(41.7)$ \\
\hline & $30-34$ & $18(17.3)$ & $24(11.5)$ & $42(13.5)$ \\
\hline & $35-39$ & $10(9.6)$ & $9(4.3)$ & $19(6.1)$ \\
\hline & $40-44$ & $1(0.9)$ & $0(0)$ & $1(0.3)$ \\
\hline \multirow{3}{*}{ Parity } & $\mathrm{I}$ & $10(9.6)$ & $50(24)$ & $60(19.2)$ \\
\hline & II-IV & $62(59.6)$ & $129(62)$ & $191(61.2)$ \\
\hline & $\geq \mathrm{V}$ & $32(30.8)$ & $29(13.9)$ & $61(19.6)$ \\
\hline \multirow{2}{*}{ ANC follow up } & Yes & $92(88.5)$ & $185(88.9)$ & $277(88.8)$ \\
\hline & No & $12(11.5)$ & $23(11.1)$ & $35(11.2)$ \\
\hline
\end{tabular}




\begin{tabular}{|c|c|c|c|c|}
\hline \multirow{2}{*}{ LNMP } & Known & $24(23.1)$ & $48(23.1)$ & $72(23.1)$ \\
\hline & Unknown & $80(76.9)$ & $160(76.9)$ & $240(76.9)$ \\
\hline \multirow{3}{*}{$\begin{array}{c}\text { Self-history of twin } \\
\text { pregnancy }\end{array}$} & Yes & $3(2.9)$ & $4(1.9)$ & $7(2.2)$ \\
\hline & $\mathrm{No}$ & $47(45.2)$ & $95(45.7)$ & $142(45.5)$ \\
\hline & Unknown & $54(51.9)$ & $109(52.4)$ & $163(52.3)$ \\
\hline \multirow{3}{*}{$\begin{array}{l}\text { Family history of twin } \\
\text { pregnancy }\end{array}$} & Yes & $9(8.6)$ & $4(1.9)$ & $13(4.2)$ \\
\hline & No & $69(66.3)$ & $139(66.8)$ & $208(66.7)$ \\
\hline & Unknown & $26(25)$ & $65(31.3)$ & $91(29.1)$ \\
\hline
\end{tabular}

ANC: Antenatal Care; LNMP: Last Normal Menstrual Period

Table 2: Maternal complications of twin deliveries at Nekemte Referral Hospital from March 1, 2016 to February 29, 2017

\begin{tabular}{|c|c|c|c|c|c|c|}
\hline \multicolumn{2}{|c|}{ Maternal complications } & $\begin{array}{c}\text { Cases (Twin) }(\mathrm{N}=104) \\
\mathrm{N}(\%)\end{array}$ & $\begin{array}{c}\text { Controls (singleton) } \\
(\mathrm{N}=208)\end{array}$ & Total $(\mathrm{N}=312) \mathrm{N}(\%)$ & $\mathrm{OR}^{*}(95 \% \mathrm{CI})$ & p-value \\
\hline \multirow{2}{*}{ HDP } & Yes & $24(23.1)$ & $15(7.2)$ & $39(12.5)$ & \multirow{2}{*}{$2.1(1.54,2.86)$} & \multirow{2}{*}{0.001} \\
\hline & No & $80(76.9)$ & $193(92.8)$ & $273(87.5)$ & & \\
\hline \multirow{2}{*}{ GDM } & Yes & $2(1.9)$ & $0(0)$ & $2(0.6)$ & \multirow{2}{*}{$3.03(2.59,3.56)$} & \multirow{2}{*}{0.045} \\
\hline & $\mathrm{No}$ & $102(98.1)$ & $208(100)$ & $310(99.4)$ & & \\
\hline \multirow{2}{*}{$\mathrm{APH}$} & Yes & $7(6.7)$ & $5(2.4)$ & $12(3.8)$ & \multirow{2}{*}{$1.80(1.09,2.99)$} & \multirow{2}{*}{0.061} \\
\hline & No & $97(93.3)$ & $203(97.6)$ & $300(96.2)$ & & \\
\hline \multirow{2}{*}{ PROM } & Yes & $14(13.5)$ & $10(4.8)$ & $24(7.7)$ & \multirow{2}{*}{$1.87(1.28,2.73)$} & \multirow{2}{*}{0.007} \\
\hline & No & $89(85.5)$ & $198(95.2)$ & $288(92.3)$ & & \\
\hline \multirow{2}{*}{ Preterm delivery } & Yes & $18(17.3)$ & $4(1.9)$ & $22(7.1)$ & \multirow{2}{*}{$2.76(2.12,3.40)$} & \multirow{2}{*}{0.001} \\
\hline & No & $86(82.7)$ & $204(98.1)$ & $290(92.9)$ & & \\
\hline \multirow{2}{*}{ Cord prolapse } & Yes & $6(5.8)$ & $2(1)$ & $8(2.5)$ & \multirow{2}{*}{$2.33(1.51,3.84)$} & \multirow{2}{*}{0.011} \\
\hline & No & $98(94.2)$ & $206(99)$ & $304(97.5)$ & & \\
\hline \multirow{2}{*}{ OL } & Yes & $1(1)$ & $8(3.8)$ & $9(2.9)$ & \multirow{2}{*}{$0.327(0.05,2.09)$} & \multirow{2}{*}{0.152} \\
\hline & $\mathrm{No}$ & $103(99)$ & $200(96.2)$ & $303(97.1)$ & & \\
\hline \multirow{2}{*}{ Cesarean delivery } & Yes & $46(44.2)$ & $29(13.9)$ & $75(24)$ & \multirow{2}{*}{$2.50(1.88,3.34)$} & \multirow{2}{*}{0.001} \\
\hline & No & $58(55.8)$ & $179(86.1)$ & $237(76)$ & & \\
\hline \multirow{2}{*}{ PPH } & Yes & $10(9.6)$ & $14(6.7)$ & $24(7.7)$ & \multirow{2}{*}{$1.27(0.77,2.11)$} & \multirow{2}{*}{0.369} \\
\hline & $\mathrm{No}$ & $94(90.4)$ & $194(93.3)$ & $288(92.3)$ & & \\
\hline \multirow{2}{*}{ Anemia } & Yes & $19(18.3)$ & $16(7.7)$ & $35(11.2)$ & \multirow{2}{*}{$1.77(1.24,2.52)$} & \multirow{2}{*}{0.005} \\
\hline & $\mathrm{No}$ & $85(81.7)$ & $192(92.3)$ & $277(88.8)$ & & \\
\hline \multirow{2}{*}{ Hysterectomy } & Yes & $1(0.9)$ & $2(1)$ & $3(0.9)$ & \multirow{2}{*}{$1.00(0.20,4.99)$} & \multirow{2}{*}{1} \\
\hline & $\mathrm{No}$ & $103(99.1)$ & $206(99)$ & 309 (99) & & \\
\hline Need for blood & Yes & $4(3.8)$ & $3(1.5)$ & $7(2.2)$ & $1.74(0.90,3.38)$ & 0.178 \\
\hline
\end{tabular}

HDP: Hypertensive Disorders of Pregnancy; GDM: Gestational Diabetes Mellitus; APH: Antepartum Hemorrhage; PROM: Premature Rupture of Membranes; OL: Obstructed Labor; PPH: Postpartum Hemorrhage; SSI: Surgical Site Infection

\section{DISCUSSION}

The magnitude of twin delivery in this study was 28.6 per 1000 deliveries. This is higher than other previous studies in Ethiopia such as study in Addis Ababa (24.0 per 1000 deliveries), Mekele (13.7 per 1000 deliveries) and Gondar (14.4 per 1000 deliveries) $[9,10]$. This finding is also higher than studies in other African countries like Egypt (17.7 per 1000 deliveries) and Sudan (20.8 per 1000 deliveries) [11-13].The relatively higher magnitude of twin delivery may be explained by the fact that the hospital was the only referral hospital in western Ethiopia, at the time of study, which was receiving cases of twin pregnancy from the surrounding health facilities. On the other hand, similar studies in other African countries like Nigeria, Democratic Republic Congo and Niger showed higher prevalence of twin delivery when compared to the current study [14]. The variation could be due to the ethnic differences in Africa.
Twin deliveries, in comparison with singletons, are associated with increased incidence of maternal complications [5,12]. The likelihood of developing hypertensive disorder of pregnancy and antepartum hemorrhage increased by about two and three folds in twin deliveries as compared to singleton deliveries. These findings are consistent with similar study conducted at Jimma university specialized hospital and Nigeria tertiary hospital. The risk of having gestation diabetes mellitus in twin delivery was increased by about three folds. This is somewhat higher than the previous studies on twin pregnancy and thus we recommend other researchers to give special attention to the association between twining and gestation diabetes mellitus [5,15].

The risks of developing premature rupture of membranes, cord prolapse and preterm delivery in twin delivery was higher when compared to singleton delivery. This could be explained by the increased intrauterine pressure in twin pregnancy. The current 
finding is consistent with similar studies in Ethiopia and other Africa countries [5,6,15].

Like other studies $[6,15]$, anemia was more common in twin deliveries. It is probably explained by the physiologic increased iron demand during pregnancy, and the greater risk of bleeding during and after delivery in twin deliveries. The other important complication after twin delivery was puerperal sepsis. Mothers with twin deliveries were twice at increased risk of having this condition which is among the leading causes of maternal deaths. It might result from different factors like premature rupture of membrane, anemia, preterm delivery, cesarean delivery and uterine manipulations for the other complications.

In this study, $44.2 \%$ of twin deliveries and $13.9 \%$ of singleton deliveries were Cesarean deliveries. This finding is higher than study done at Azare, Nigeria i.e.18.5\% in twins [16] and Global Network for women's and children's health research in 6 different low and mid income countries $(18.1 \%$ in twin pregnancies and $9.5 \%$ in singleton pregnancies) [17]. This increased cesarean delivery rate in twin pregnancies in this study may be due to increased occurrence of obstetric complications like hypertensive disorders, antepartum hemorrhage, premature rupture of membranes and cord prolapse.

Interestingly, in this particular study, twin pregnancies were at lower risk of developing obstructed labor. It could be due to the presence of other obstetrics complications that make these patients visit health facility before they develop obstructed labor.

This study may have its own limitation in that all the estimates of odds ratio were based on crude estimate and other possible confounding factors were not controlled. This was because of the large number of multiple complications considered for intervention purposes. Future studies may address this by doing multivariate analysis by focusing on some specific maternal complications.

\section{CONCLUSION}

In conclusion, despite the above limitations, the magnitude of twin delivery in this study was high and many maternal complications were identified when compared to singleton deliveries. Thus, twin deliveries need greater attention during pregnancy, delivery and after delivery.

\section{ACKNOWLEDGEMENT}

The authors would like to thank Jimma University Specialized Hospital for funding this study. Our sincere gratitude also goes to all supervisors, data collectors and study participants for their cooperation and support during the study period.

\section{AUTHORS' CONTRIBUTION}

$\mathrm{AA}, \mathrm{TT}$ and DB were involved in all processes of this research work, including conception, design, and supervision of data collection, data analysis and write up of the manuscript. All authors read and approved the final manuscript.

\section{COMPETING INTEREST}

The authors declare that they have no any competing interests.

\section{REFERENCES}

1. Bakare AA, Akinboro A, Azeez MA. Frequency of twinning in southwest Nigeria. Indian J Human Genetics. 2008;14(2):41-47.

2. Tokwankwo UU, Aniebue E, Ezenkwele MI, Nwafor I. Outcome of twin pregnancies in UNTH Enugu. Niger J Clin Pract. 2013;16:67-81.

3. Steven GG, Jennifer RN, Henry LG, Joe LS, Eric RMJ, Mark L, et al. Obstetrics normal and problem pregnancies, 6th edition. Elsevier. 2012.

4. Tilahun T, Araya F, Tura G. Incidence and Risk Factors of Twin Pregnancy at Jimma University Specialized Hospital, Southwest Ethiopia. Epidemiology. 2015;5(2).

5. Bekabil TT, Tsaedu FA, Debelew GT. Maternal complications of twin deliveries in Jimma University Specialized Hospital, Southwest Ethiopia: A facility-based cohort study. Gaziantep Med J. 2015;21(2):84-89

6. Dera A, Breborowiczg H, Keith L. Twin pregnancy-physiology, complications and the mode of delivery. Archives of Perinatal Medicine. 2007;13:1673-1675.

7. Ibrahim I, Oyeyemi A, Onwudiegwu A. Twin pregnancies in the Niger Delta of Nigeria: a four-year review. Int J Womens Health. 2012;4:245-249.

8. Godwin OA, Teddy EA, Olatunde ON, Richard A, Nathaniel DA. Review of Twin Pregnancies in a Tertiary Hospital in Abuja, Nigeria. Journal of Health, Population and Nutrition. 2013;31(2):272-277.

9. Gessessew A. Twin deliveries in a zonal hospital: ten years retrospective study. Ethiop Med J. 2007;45(1):55-59.

10. Korsak VS. Incidence and some perinatal problems of multiple pregnancies in a central referral hospital, Addis Ababa. Ethiop Med J. 27(4):217-221.

11. Zein AZ. The frequency of multiple births in Gondar Hospital Northwestern Ethiopia. Ethiop Med J. 1989;27(1):21-26.

12. Ananth CV, Chauhan SP. Epidemiology of Twinning in Developed Countries. Seminars in Perinatology. 2012;36(3):156-161.

13. Smits J, Monden C. Twinning across the Developing World. PLoS One. 2011;6(9):e25239.

14. Vogel JP, Torloni MR, Seuc A, Betran AP, Widmer M, Souza JP, et al. Maternal and Perinatal Outcomes of Twin Pregnancy in 23 Low- and Middle-Income Countries. PLoS One. 2013;8(8):e70549.

15. Obiechina NJ, Okolie VE, Eleje GU, Okechukwu ZC, Anemeje OA. Twin versus singleton pregnancies: the incidence, pregnancy complications, and obstetric outcomes in a Nigerian tertiary hospital. Int J Womens Health. 2011;3:227-230.

16. Ibrahim SM, Kullima AA, Bilkisu I, Umar NI, Bakari MA. Outcome of Twin pregnancies in Federal Medical Center Azare, Nigeria. Biomed J. 2013;10:1-9.

17. Edward AL. Perinatal Outcomes of Multiple Pregnancies in Kenya, Zambia, Pakistan, India, Guatemala and Argentina: A Global Network Study. Am J Perinatol. 2014;31(2):125-132. 